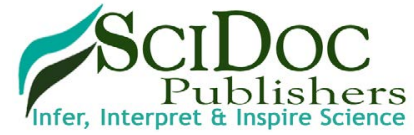

\title{
Technological Options for Promoting Adaptive Behaviors of Children with Fragile X Syndrome
}

Editorial

Stasolla $\mathrm{F}^{1^{*}}$, Perilli $\mathrm{V}^{2}$, Boccasini $\mathrm{A}^{3}$

${ }^{1}$ Department of Neurosciences, University of Bari, Italy.

${ }^{2}$ Lega del Filo d'Oro Research Center, Molfetta, Italy.

${ }^{3}$ Lega del Filo d'Oro Research Center, Termini Imerese, Italy.

Fragile $\mathrm{X}$ syndrome (FXS) is a genetic pathology due to an excessive length of a repetitive sequence of trinucleotides (CGG) in a specific gene (FMR1), matched to FMR1 protein, which is primarily responsible for the regular brain developing and functioning. It represents one of the most usual cause of developmental disabilities with learning difficulties as consequence of intellectual, communicative and social disorders. Additionally, anxiety, hyperactivity, seizures, gaze avoidance and autism spectrum disorders are frequently described within its patterns, basically occurring in males. FXS physical characteristics usually include long and narrow visage, large ears, prominent jaws and foreheads. Stereotypic behaviors, aggression and self-injuries are equally described among this population [1-3]. Accordingly, individuals with FXS may be entirely considered as affected by severe to profound developmental disabilities. One way to enable the latter persons with the independent access to positive stimulation is the use of assistive technology (AT) [4]. It refers to any technological piece, device, tool or equipment enhancing selfdetermination [5]. Despite its large and wide use among children with developmental disabilities, few studies have been carried out on the use of AT within FXS population $[6,7]$.

For instance, Riley et al., [8] conducted a pilot study aimed at assessing the use of an AT device to improve daily living of a young woman with FXS who was estimated within a low level of intellectual functioning. Baseline data were collected on a paper sheet by both the participant and her mother, based upon a series of activities of daily living, which the young woman was unable to correctly perform through a low-tech device such as a written checklist. Subsequently, a high-tech equipment (i.e., Tickle Box) was introduced. Data were collected using the same format. Results emphasized a performance improvement with respect to the baseline. Mirrett, Roberts and Price [9] described speech-language pathologists' impressions of the communication difficulties of young males with FXS and assessed the needs for individualized AT-based interventions. Thus, within a regional study, which recruited 51 speech-language pathologists who provided interventions for males with FXS within a range age between 2 and 9 years, a survey was conducted. The majority of the professionals involved pointed out the necessity for both low and high-tech solutions aimed at increasing non-verbal and/ or minimally verbal children skills focused on listening, auditory comprehension and conversation. Moreover, before planning a customer-tailored intervention for children with FXS, the specific behavioral pattern (i.e., anxiety, attention deficits and sensory overload problems) should be carefully examined. Stasolla et al. [10] assessed occupation and choice capacities of two boys (i.e., 8.7 and 9.7 years old respectively) with FXS through technological supports (i.e., optic sensors such as photocells). A second objective of the study was to reduce stereotypic behaviors (i.e., hand mouthing and eye poking). Indices of happiness as outcome measure of participants' quality of life were also recorded as to outline the program's effectiveness. Both participants improved their performances during intervention phases if compared to the baselines. An extension of such program was recently carried out by Stasolla, Perilli, Damiani and Albano [11] who exposed three participants with FXS (aged of 8.8, 9.4 and 10.5 respectively) to an AT-based rehabilitative strategy for promoting a new adaptive response (i.e., inserting two different objects in two different containers within a time interval of $3 \mathrm{~s}$. A three months followup and a social validation assessment involving 30 parents of children with severe to profound developmental disabilities were additionally conducted. Data showed that all participants increased the adaptive responding and reduced the stereotypic behaviors during the intervention phases. They all consolidated their performance within the follow-up and social raters favorably scored the use of AT. The aforementioned empirical evidences suggest that further extensions of the AT for children with FXS is undoubtedly warranted.

In light of the above, and depending upon the levels of functioning of the participants involved, one may envisage different AT-based programs. For example, for very low functional individuals who dispose of a very limited behavioral repertoire, one may argue on

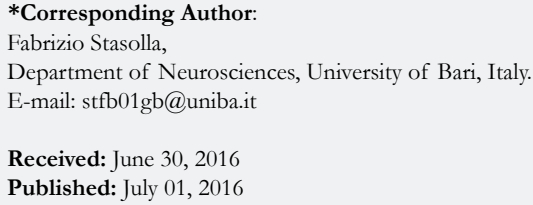

Copyright: Stasolla $\mathbf{F}^{\circ}$ 2016. This is an open-access article distributed under the terms of the Creative Commons Attribution License, which permits unrestricted use, distribution and reproduction in any medium, provided the original author and source are credited. 
the use of a unique microswitch (i.e., a basic AT tool ensuring participant's self-determination) for promoting the independent access to positive stimulation [12]. Else, one may design a choice-opportunity based program with two different behavioral responses detected by two different microswitches enabling the participants with two different categories of sensorial stimuli (e.g., visual and auditory). Otherwise, a cluster technology may be considered for pursuing the dual goal of increasing the adaptive responding and reducing a challenging behavior [13]. Furthermore, one may adopt a computer-based intervention for providing request and choice chances of desired items [14]. Finally, preference and social validation assessments should be carried out $[15,16]$. Consequently, new research perspectives within this framework should deal with the following topics: (a) further extensions of participants with FXS involved, (b) new AT-based setups for responding to different individualized needs, (c) assessing the preference checks of participants involved and (d) conducting new validation assessments with different groups of external raters (e. g., caregivers, parents, professionals, students and teachers).

\section{References}

[1]. Moskowitz LJ, Jones EA (2015) Uncovering the evidence for behavioral interventions with individuals with fragile $\mathrm{X}$ syndrome: A systematic review. Res Dev Disabil 38: 223-241.

[2]. Hagerman RJ, Polussa J (2015) Treatment of the psychiatric problems associated with fragile X syndrome. Current Opinion in Psychiatry 28(2): 107-112.

[3]. Tonnsen BL, Grefer ML, Hatton DD, Roberts JE (2015) Developmental trajectories of attentional control in preschool males with fragile X syndrome. Res Dev Disabil 36: 62-71.

[4]. Stasolla F, Perilli V, Boccasini A (2016) Assistive Technologies for Persons with Severe-Profound Intellectual and Developmental Disabilities In: Computer-Assisted and Web-Based Innovations in Psychology, Special Education, and Health. 287-310.
[5]. Stasolla F, Perilli V (2015) Micro switch-based programs (MBP) to promote communication, occupation, and leisure skills for children with multiple disabilities: A literature overview In: Recent Advances in Assistive Technologies to Support Children with Developmental Disorders. Chapter (9): 195-216.

[6]. Deroche CB, Holland MM, McDermott S, Royer JA, Hardin JW, et al., (2015) Development of a tool to describe overall health, social independence and activity limitation of adolescents and young adults with disability. Res Dev Disabil 38: 288-300.

[7]. Jawaid A, Riby DM, Owens J, White SW, Tarar T, et al., (2012) 'Too withdrawn' or 'too friendly': Considering social vulnerability in two neuro-developmental disorders. J Intellect Disabil Res 56(4): 335-350.

[8]. Riley K, Bodine C, Hills J, Gane LW, Sandstrum J, et al., (2001) The tickle box assistive technology device piloted on a young woman with fragile $\mathrm{X}$ syndrome. Ment Health Asp Dev Disabil 4(4): 138-142.

[9]. Mirrett PL, Roberts JE, Price J (2003) Early intervention practices and communication intervention strategies for young males with fragile $\mathrm{X}$ syndrome. Lang Speech Hear Serv Sch 34: 320-331.

[10]. Stasolla F, Damiani R, Perilli V, Di Leone A, Albano V, et al., (2014) Technological supports to promote choice opportunities by two children with fragile X syndrome and severe to profound developmental disabilities. Res Dev Disabil 35(11): 2993-3000.

[11]. Stasolla F, Perilli V, Damiani R, Albano V (2016) Assistive technology to promote occupation and reduce mouthing by three boys with fragile $\mathrm{X}$ syndrome. Dev Neurorehabilitation 7: 1-9.

[12]. Lancioni GE, O'Reilly MF, Singh NN, Stasolla F, Manfredi F, et al., (2004) Adapting a grid into a micro switch to suit simple hand movements of a child with profound multiple disabilities. Percept Mot Skills 99(2): 724-728.

[13]. Stasolla F, Perilli V, Damiani R, Caffò AO, Di Leone A, et al., (2014) micro switch-cluster program to enhance object manipulation and to reduce hand mouthing by three boys with autism spectrum disorders and intellectual disabilities. Res Autism Spectr Disord 8(9): 1071-1078.

[14]. Stasolla F, Caffò AO, Picucci L, Bosco A (2013) Assistive technology for promoting choice behaviors in three children with cerebral palsy and severe communication impairments. Res Dev Disabil 34(9): 2694-2700.

[15]. Stasolla F, Damiani R, Caffò AO (2014) Promoting constructive engagement by two boys with autism spectrum disorders and high functioning through behavioral interventions. Res Autism Spectr Disord 8(4): 376-380.

[16]. Stasolla F, Perilli V, Damiani R (2014) Self monitoring to promote on-task behavior by two high functioning boys with autism spectrum disorders and symptoms of ADHD. Res Autism Spectr Disord 8(5): 472-479. 